\title{
QUALITY OF LIFE IN PATIENTS WITH AGE-RELATED MACULAR DEGENERATION WITH MONOCULAR AND BINOCULAR LEGAL BLINDNESS
}

\author{
Roberta Ferrari Marback, Otacílio de Oliveira Maia Júnior, Fábio Barreto \\ Morais, Walter Yukihiko Takahashi
}

\begin{abstract}
Marback RF, Maia Júnior OO, Morais FB, Takahashi WY. Quality of life in patients with Age-Related Macular Degeneration with monocular and binocular legal blindness. Clinics. 2007; 62(5):573-8.
\end{abstract}

OBJECTIVE: To evaluate the quality of life for persons affected by age-related macular degeneration that results in monocular or binocular legal blindness.

METHODS: An analytic transversal study using the National Eye Institute Visual Functioning Questionnaire (NEI VFQ-25) was performed. Inclusion criteria were persons of both genders, aged more than 50 years old, absence of cataracts, diagnosis of agerelated monocular degeneration in at least one eye and the absence of other macular diseases. The control group was paired by sex, age and no ocular disease.

RESULTS: Group 1 (monocular legal blindness) was composed of 54 patients $(72.22 \%$ females and $27.78 \%$ males, aged 51 to 87 years old, medium age $74.61 \pm 7.27$ years); group 2 (binocular legal blindness ) was composed of 54 patients ( $46.30 \%$ females and $53.70 \%$ males aged 54 to 87 years old, medium age $75.61 \pm 6.34$ years). The control group was composed of 40 patients ( $40 \%$ females and $60 \%$ males, aged 50 to 81 years old, medium age $65.65 \pm 7.56$ years). The majority of the scores were statistically significantly higher in group 1 and the control group in relation to group 2 and higher in the control group when compared to group 1.

CONCLUSIONS: It was evident that the quality of life of persons with binocular blindness was more limited in relation to persons with monocular blindness. Both groups showed significant impairment in quality of life when compared to normal persons.

KEY-WORDS: Retina/abnormalities. Macular degeneration/complications. Blindness/psychology. Vision. Llow/etiology. Quality of life/psychology. Sickness impact profile.

\section{INTRODUCTION}

Age-related macular degeneration (AMD) is the main cause of irreversible visual loss in individuals over the age of 65 , with an estimated prevalence of close to $10 \%$ in individuals between 65 and 75 years and $30 \%$ in individuals over 75 years old. ${ }^{1,2}$ As a consequence of the increased life expectancy of the world population, an increase in the number of people with AMD is foreseen for this millen-

Ophthalmology - University of Sao Paulo Medical School General Hospital, São Paulo/Brazil

Email: robertamarback@uol.com.br

Received for publication on June 08, 2007

Accepted for publication on June 27, 2007 nium. ${ }^{3}$ Despite scientific advances and the discovery of new drugs for the treatment of this disease, the therapies available to patients are somewhat limited and can only be applied in specific cases. ${ }^{4,5}$

The progressive deterioration of central vision that is typical of this disease generally incapacitates the elderly, hindering daily activities and, consequently, their quality of life. Williams et al. applied evaluation instruments on patients with AMD in order to establish scores related to emotional and quality of life aspects and obtained results similar to those found in diseases such as AIDS, chronic obstructive pulmonary disease, cardiac disorders, melanoma and leukemia. Furthermore, it was shown that most individuals with AMD reported the ocular disease as being their 
main limiting factor. ${ }^{6}$

The purpose of this study was to evaluate the quality of life in patients with AMD with monocular or binocular legal blindness with the 25-item National Eye Institute Visual Function Questionnaire (NEI VFQ-25).

\section{MATERIALS AND METHODS}

A cross-sectional analytical study was conducted using the NEI VFQ-25, which was applied as an interview. The readily available sample consisted of patients seen at the Retina Service of the Ophthalmology Clinic, University of Sao Paulo General Hospital, from July to December 2006. The following inclusion criteria were established in order to obtain the sample: individuals of both sexes with advanced AMD and an absence of cataracts or other maculopathies who were willing to be interviewed. The control group consisted of individuals of both sexes who had no ocular diseases and a visual acuity higher than or equal to $20 / 40$ in both eyes.

The respondents were classified into two groups according to visual acuity (VA) in both eyes. Group 1 included individuals with legal blindness in one eye (VA $=20 / 200$ or worse) and a contralateral eye with VA $=20 / 60$ or worse; group 2 included individuals with legal blindness in both eyes. The concept of blindness was the pattern used in the United States of America. ${ }^{7}$ The "VA $=20 / 60$ or worse" criterion in the contralateral eye of the patients in Group 1 was established according to a previous study which revealed that there is functional impairment at this acuity level, such as difficulties reading and recognizing people. ${ }^{6}$

Before starting the interviews, study objectives and methods were explained to the patients, who were assured privacy and anonymity of the information they provided, as well as the absence of damage and losses with regards to the treatment offered at the ophthalmology clinic.

The NEI VFQ-25 is a closed questionnaire, whose validity and reliability has been proven in different populations, and consists of 25 questions, grouped into 12 subdomains, including one or more questions each. The questionnaire was applied in Portuguese, with the translation performed by Sant'Anna et al. ${ }^{8}$ The subdomains include general health, general vision, ocular pain, near activities, far activities, social functioning, mental health, role difficulties, dependence, driving difficulties, color vision and peripheral vision. The scores range from 0 to 100 , where 0 represents a more severe visual impairment and 100 , better vision. The score for each subdomain was calculated by a simple mean of the corresponding answers; the higher the score, the better the respondent's quality of life. ${ }^{9}$
Initially, all variables were descriptively analyzed. The analysis of the quantitative variables included minimum and maximum values, as well as the calculation of the mean, standard deviation and median values. Absolute and relative frequencies were calculated for the qualitative variables. Student's t test was used to analyze the hypothesis of equality of means among the groups, and the MannWhitney's nonparametric test was used when the assumption of data normality was rejected. In order to test the groups' homogeneity with regards to proportions, we applied the chi-squared test or Fischer's exact test (for expected frequencies of less than 5). The level of significance used for the tests was of $5 \% .{ }^{10}$

The study was previously approved by the Ethics Commission of the University of Sao Paulo General Hospital, and all patients signed an Informed Consent Form.

\section{RESULTS}

The sample was comprised of 108 patients, 54 each for groups 1 and 2. In group 1, 72.22\% were women, and $27.78 \%$ were men; they were between the ages of 51 and 87 , with a mean age of $74.61 \pm 7.27$ years. In group 2 , $46.30 \%$ were women, and $53.70 \%$ were men; they were between the ages of 54 and 87, with a mean age of 75.61 \pm 6.34 years. The sociodemographic characteristics of both groups are shown in Table 1. The control group consisted in 40 patients, $40 \%$ women and $60 \%$ men, between the ages of 50 and 81 ; the mean age was $65.65 \pm 7.56$ years.

The groups only showed a significant difference regarding gender distribution. When groups 1 and 2 were compared to the control group, it was evident that the age of those in the control group was significantly lower. No other differences were observed.

All of the NEI VFQ - 25 subdomain scores with the respective comparative statistical analyses between groups are presented in Tables 2, 3 and 4. Most of the scores were significantly higher in group 1 and the control group than in group 2; scores were also significantly higher in the control group when compared to group 1 .

\section{DISCUSSION}

The NEI VFQ - 25 is an instrument for the psychometric measurement of an individual's quality of life that is used to assess patients with ocular diseases leading to poor vision. ${ }^{11-14}$ The questionnaire comprises items addressing aspects such as physical, mental and social well-being, as well as their consequences for the patient's health status; it has been validated in individuals with a variety of chronic ocular diseases, such as AMD, glaucoma, diabetic retin- 
Table 1 - Sociodemographic characteristics of patients with age-related macular degeneration with monocular (Group 1) and binocular (Group 2) legal blindness at the University of Sao Paulo General Hospital in 2006.

\begin{tabular}{|c|c|c|c|c|c|}
\hline Characteristics & \multicolumn{2}{|c|}{ Group 1} & \multicolumn{2}{|c|}{ Group 2} & $\mathrm{p}$ \\
\hline Age & \multicolumn{2}{|c|}{ 74. 61 years $\pm 7.27(\mathrm{SD})$} & \multicolumn{2}{|c|}{75.61 years $\pm 6.34(\mathrm{SD})$} & $0.448 *$ \\
\hline Sex & $\mathrm{n}$ & $(\%)$ & $\mathrm{n}$ & $(\%)$ & 0.006 \\
\hline Female & 39 & 72.22 & 25 & 46.30 & \\
\hline Male & 15 & 27.78 & 29 & 53.70 & \\
\hline Education & & & & & $0.874 * *$ \\
\hline Primary & 32 & 59.26 & 35 & 64.81 & \\
\hline Secondary & 14 & 25.93 & 11 & 20.37 & \\
\hline Superior & 5 & 9.26 & 4 & 7.41 & \\
\hline Did not study & 3 & 5.56 & 4 & 7.41 & \\
\hline Marital Status & & & & & $0.771 * *$ \\
\hline Married & 29 & 53.70 & 26 & 48.15 & \\
\hline Widow & 25 & 46.30 & 26 & 48.15 & \\
\hline Single & - & - & 1 & 1.85 & \\
\hline Divorced & - & - & 1 & 1.85 & \\
\hline Remunerated work & & & & & $1.000 * *$ \\
\hline Yes & 3 & 5.56 & 3 & 5.56 & \\
\hline No & 51 & 94.44 & 51 & 94.44 & \\
\hline Reasons for not engaging in remunerated work & & $\mathrm{n}=51$ & & & $0.229 * *$ \\
\hline Retired & 30 & 58.82 & 36 & 70.59 & \\
\hline Pensioner & 19 & 37.25 & 12 & 23.53 & \\
\hline Unable to & 1 & 1.96 & - & - & \\
\hline Cannot find a job & 1 & 1.96 & 3 & 5.88 & \\
\hline
\end{tabular}

$\mathrm{n}=108 ; *$ Student's t test; **Fischer's exact test. Significance level of 0.05

Table 2 - Comparison of the NEI VFQ - 25 subdomain scores based on the responses of patients with age-related macular degeneration and either monocular (group 1) or binocular (group 2) legal blindness at the University of Sao Paulo General Hospital in 2006

\begin{tabular}{lccc}
\hline Subdomain & Group 1* & Group 2* & $\mathrm{p}^{* *}$ \\
\hline General health & $39.81 \pm 19.13$ & $30.55 \pm 21.53$ & 0.023 \\
General vision & $58.51 \pm 14.97$ & $33.33 \pm 16.48$ & $<0.001$ \\
Ocular pain & $89.12 \pm 13.95$ & $78.70 \pm 17.61$ & 0.001 \\
Near activities & $68.67 \pm 17.35$ & $24.07 \pm 17.03$ & $<0.001$ \\
Distance activities & $66.82 \pm 18.34$ & $25.77 \pm 16.92$ & $<0.001$ \\
Social functioning & $88.19 \pm 17.74$ & $57.40 \pm 32.62$ & $<0.001$ \\
Mental health & $73.03 \pm 18.28$ & $36.92 \pm 16.25$ & $<0.001$ \\
Role difficulties & $65.04 \pm 23.83$ & $27.08 \pm 17.80$ & $<0.001$ \\
Dependency & $72.99 \pm 23.40$ & $38.27 \pm 21.32$ & $<0.001$ \\
Color vision & $91.66 \pm 18.17$ & $68.51 \pm 26.68$ & $<0.001$ \\
Peripheral vision & $79.62 \pm 18.85$ & $51.38 \pm 27.65$ & $<0.001$ \\
\hline
\end{tabular}

* Mean \pm standard deviation

** Mann-Whitney's nonparametric test. Significance level of 0.05

opathy, cataracts and cytomegalovirus retinitis. ${ }^{9}$

Previous studies have shown that individuals with AMD are susceptible to depression, social isolation, emotional stress, as well as feelings of fear, frustration and sadness. ${ }^{4,11,15}$ This occurs because most of those in the age group affected by the disease are retired and usually indulge in activities that require good eyesight, such as reading, watching TV, playing cards and sewing. In addition to these mental problems, these patients become more susceptible to falls, which increases the risk of fractures due
Table 3 - Comparison of the NEI VFQ - 25 subdomain scores based on the responses of patients with age-related macular degeneration and monocular (group 1) legal blindness and the control group at the University of Sao Paulo General Hospital in 2006

\begin{tabular}{llll}
\hline Subdomain & Group $1 *$ & Control Group* & $\mathrm{p}^{* *}$ \\
\hline General health & $39.81 \pm 19.13$ & $50.62 \pm 20.79$ & 0.0165 \\
General vision & $58.51 \pm 14.97$ & $78.50 \pm 12.31$ & $<0.001$ \\
Ocular pain & $89.12 \pm 13.95$ & $95.54 \pm 4.81$ & 0.0050 \\
Near activities & $68.67 \pm 17.35$ & $94.87 \pm 6.68$ & $<0.001$ \\
Distance activities & $66.82 \pm 18.34$ & $94.29 \pm 7.75$ & $<0.001$ \\
Social functioning & $88.19 \pm 17.74$ & $97.56 \pm 0.00$ & 0.0013 \\
Mental health & $73.03 \pm 18.28$ & $96.30 \pm 1.92$ & $<0.001$ \\
Role difficulties & $65.04 \pm 23.83$ & $97.56 \pm 0.00$ & $<0.001$ \\
Dependency & $72.99 \pm 23.40$ & $97.56 \pm 0.00$ & $<0.001$ \\
Color vision & $91.66 \pm 18.17$ & $100.00 \pm 0.00$ & 0.0925 \\
Peripheral vision & $79.62 \pm 18.85$ & $99.37 \pm 3.95$ & $<0.001$ \\
\hline
\end{tabular}

* Mean \pm standard deviation

** Mann-Whitney's nonparametric test. Significance level of 0.05

to poor vision. ${ }^{16}$ Furthermore, the consequences of AMD in daily activities, concerning the individual's social and emotional aspects, are precariously described in the literature. ${ }^{6,17}$ In the national literature, we found no register of studies on the impact of AMD on patients' lives.

Using the NEI VFQ - 25, Varma et al. observed that individuals with moderate or serious visual impairments (VA $=20 / 80$ or worse) in both eyes, compared to those with moderate bilateral impairments (VA $=20 / 40-20 / 60)$ or unilateral impairment, had difficulties with visual function, 
Table 4 - Comparison of the NEI VFQ - 25 subdomain scores based on the responses of patients with age-related macular degeneration and legal binocular (group 2) blindness and the control group at the University of Sao Paulo General Hospital in 2006

\begin{tabular}{llll}
\hline Subdomain & Group $2 *$ & Control Group* & $\mathrm{p}^{* *}$ \\
\hline General health & $30.55 \pm 21.53$ & $50.62 \pm 20.79$ & $<0.001$ \\
General vision & $33.33 \pm 16.48$ & $78.50 \pm 12.31$ & $<0.001$ \\
Ocular pain & $78.70 \pm 17.61$ & $95.54 \pm 4.81$ & $<0.001$ \\
Near activities & $24.07 \pm 17.03$ & $94.87 \pm 6.68$ & $<0.001$ \\
Distance activities & $25.77 \pm 16.92$ & $94.29 \pm 7.75$ & $<0.001$ \\
Social functioning & $57.40 \pm 32.62$ & $97.56 \pm 0.00$ & $<0.001$ \\
Mental health & $36.92 \pm 16.25$ & $96.30 \pm 1.92$ & $<0.001$ \\
Role difficulties & $27.08 \pm 17.80$ & $97.56 \pm 0.00$ & $<0.001$ \\
Dependency & $38.27 \pm 21.32$ & $97.56 \pm 0.00$ & $<0.001$ \\
Color vision & $68.51 \pm 26.68$ & $100.00 \pm 0.00$ & $<0.001$ \\
Peripheral vision & $51.38 \pm 27.65$ & $99.37 \pm 3.95$ & $<0.001$ \\
\hline
\end{tabular}

* Mean \pm standard deviation

** Mann-Whitney's nonparametric test. Significance level of 0.05

affecting near and far activities, mental health and dependency. The low scores related to dependence and mental health proved how much bilateral impairment affects the individual, resulting in loss of independence and increased levels of anxiety. ${ }^{13}$ Other authors showed that the consequences of visual loss from AMD mainly affect the patient's mental health. ${ }^{6,15,18}$ Brody et al. indicated that depression due to ocular disease is a significant problem. ${ }^{11}$

Based on the subdomains evaluated, the present study showed that the scores of group 1 were significantly higher than those of group 2, which suggests that quality of life is more affected by binocular, as compared to monocular, blindness. Nevertheless, both groups had lower scores when compared to normal individuals, suggesting that a reduction of visual acuity, such as legal blindness in one eye and subnormal vision in the other (group 1) or legal blindness in both eyes (group 2), significantly affects quality of life. With the exception of the "color vision" score, we observed that the scores of normal individuals were significantly higher than those of group 1; and all scores were higher than those of Group 2, which suggests that AMD worsens quality of life, whether it manifests as monocular or as binocular blindness. The subdomain "driving difficulties" was not addressed because it was not a part of the daily lives of the studied sample. Only a minority of the respondents mentioned this activity, which made it impossible to perform comparative analyses.

An important limitation of this study was that it did not analyze the time since disease onset because patients with sudden visual impairment (secondary to neovascular membrane) may be more affected, psychologically, than those with a slow onset (secondary to geographic atrophy). Furthermore, the sociocultural profile of the sample, comprising patients seen at a university hospital, may interfere with the results, although there was no difference between the studied groups.

AMD affects the quality of life of the elderly, and studies should be developed, not only to address the pathophysiological aspects of the disease but also to develop psychosocial treatments. Such improvements should focus on the prevention of mental problems, such as depression in the elderly, and should orient patients on how to deal with the limitations imposed by the disease.

\section{RESUMO}

Marback RF, Maia Júnior OO, Morais FB, Takahashi WY. Qualidade de vida de pacientes com Degeneração Macular Relacionada à Idade com cegueira legal monocular e binocular. Clinics. 2007; 62(5):573-8.

OBJETIVO: Avaliar a qualidade de vida de portadores de degeneração macular relacionada à idade com cegueira legal monocular e binocular.
MÉTODOS: Foi realizado estudo transversal analítico por meio do questionário National Eye Institute Visual Functioning Questionnaire (NEI VFQ-25). Os critérios de inclusão foram: indivíduos de ambos os sexos, idade maior que 50 anos, ausência de catarata, diagnóstico de degeneração macular relacionada à idade avançada em pelo menos um dos olhos, sem outras maculopatias. O Grupo Controle foi pareado por sexo, idade e sem doença ocular. 
RESULTADOS: O Grupo 1 (cegueira monocular) foi composto por 54 pacientes $(72,22 \%$ de mulheres e $27,78 \%$ de homens, idade entre 51 e 87 anos, média de 74,61 anos \pm 7,27 anos); o Grupo 2 (cegueira binocular), por 54 (46,30\% de mulheres e $53,70 \%$ de homens, idade entre 54 e 87 anos, média de 75,61 anos $\pm 6,34$ anos). O Grupo Controle foi composto por 40 pacientes $(40 \%$ de mulheres e $60 \%$ de homens, idade entre 50 e 81 anos, média de 65,65 anos \pm 7,56 anos). A maioria dos escores foi significativamente maior no Grupo 1 e no Controle em relação ao Grupo 2 e maior no Controle comparado ao Grupo 1.
CONCLUSÕES: Evidenciou-se que a qualidade de vida de indivíduos com cegueira binocular foi mais limitada em relação aos portadores de cegueira monocular. Quando comparados com indivíduos normais, ambos os grupos tiveram prejuízo na qualidade de vida foi significativo.

UNITERMOS: Retina/Anormalidades. Degeneração. Macular/complicações. Cegueira/Psicologia. Baixa Visão/ Etiologia. Qualidade de Vida/Psicologia. Perfil de Impacto da Doença.

\section{REFERENCES}

1. National Advisory Eye Council. Vision Research. A National Plan: 19992003. Bethesda, MD: US Departament of Health and Human Services, 1998; NIH Pub \# 98-4288.

2. Klein R, Klein BEK, Jensen SC, Meuer SM. The 5-year incidence and progression of age-related maculopathy: The Beaver Dam Eye Study. Ophthalmology. 1997;104:7-21.

3. Smith W, Assink J, Klein R, Mitchell P, Klaver CC, Klein BB et al. Risk factors for age-related macular degeneration: pooled findings from three continents. Ophthalmology. 2001;108:697-704.

4. Owsley C, McGwin Jr. G, Scilley K, Dreer LE, Bray CR, Mason III JO. Focus Groups with persons who have age-related macular degeneration: emotional issues. Rehabilitation Psychology. 2006;51:23-9.

5. Alexander LJ. Age-related macular degeneration: the current understanding of the status of clinicopathology, diagnosis and management. J Am Optom Assoc. 1993;64:838-50.
6. Williams RA, Brody BL, Thomas RG, Kaplan RM, Brown SI. The psychosocial impact of macular degeneration. Arch Ophthalmol 1998;116:514-20.

7. International Council of Ophthalmology. Visual Standards: Aspects and Ranges of Vision Loss with Emphasis on Population Surveys. 29 International Congress of Ophtalmology. Sydney, Austrália; April 2002.

8. Sant'Anna NV, Schor P, Lipener C, Uras R. Comparação da função visual e do índice de qualidade de vida com uso de óculos ou lente de contato progressiva. Arq Bras Oftalmol. 2006;69:349-59.

9. Mangione CM, Lee PP, Gutierrez PR, Spritzer K, Berry S, Hays RD. Development of the 25-item National Eye Institute Visual Function Questionnaire (VFQ-25). Arch Ophthalmol. 2001;119:1050-8.

10. Rosner B. Fundamentals of Biostatistics. $2^{\text {nd }}$ ed. Boston: PWS Publishers; 1986. 
11. Brody BL, Gamst AC, Williams RA, Smith AR, Lau PW, Dolnak D, Rapaport MH, Kaplan RM, Stuart IB. Depression, visual acuity, comorbidity and disability associated with age-related macular degeneration. Ophthalmology 2001;108:1893-1901.

12. Cahill MT, Banks AD, Stinnett SS, Toth CA. Vision-related quality of life in patients with bilateral severe age-related macular degeneration. Ophthalmology. 2005;112:152-8.

13. Varma R, Wu J, Chong K, Azen SP, Hays RD. Impact of severity and bilaterality of visual impairment on health-related quality of life. Ophthalmology. 2006;113:1846-53.

14. Mangione CM, Berry S, Spritzer K, Janz NK, Klein R, Owsley C, Lee PP. Identifying the content area for the 51-item National Eye Institute Visual Function Questionnaire: results from focus groups with visually impaired persons. Arch Ophthalmol. 1998;116:227-33.
15. Casten RJ, Rovner BW, Tasman W. Age-related macular degeneration and depression: a review of recent research. Curr Opin Ophthalmol. 2004;15:181-3

16. Takahashi WY. Degeneração macular relacionada à idade: DMRI. Rio de Janeiro: Cultura Médica; 2007.

17. Mitchell J, Bradley P, Anderson SJ, Ffytche T, Bradley C. Perceived quality of health care in macular disease: a survey of members of the Macular Disease Society. Br J Ophthalmol. 2002;86:777-81.

18. Mangione CM, Gutierrez PR, Orav EJ, Seddon JM. Influence of agerelated maculopathy on visual functioning and health-related quality of life. Am J Ophthalmol. 1999;128:45-53. 